\title{
The effect of phagocytosis of poly(L-lactic acid) fragments on cellular morphology and viability
}

\author{
K. H. Lam, ${ }^{1}$ J. M. Schakenraad, ${ }^{2, *}$ H. Esselbrugge, ${ }^{3}$ J. Feijen, ${ }^{3}$ and P. Nieuwenhuis ${ }^{1}$ \\ ${ }^{1}$ Department of Histology and Cell Biology, Section of Biomaterials, University of Groningen, Oostersingel 69-1, \\ 9713 EZ Groningen, The Netherlands; ${ }^{2}$ Biomedical Technology Centre, University of Groningen, Oostersingel 59, \\ Building 25, 9713 EZ Groningen, The Netherlands; ${ }^{3}$ Department of Chemical Technology, University of Twente, \\ PO Box 217, 7500 AE Enschede, The Netherlands
}

The aim of this study was to investigate the effect of phagocytosed poly(L-lactic acid) particles on the morphology and viability of phagocytes, mainly macrophages. Therefore, predegraded poly(L-lactic acid) (P-PLLA) and nontreated PLLA (N-PLLA) particles, both having diameters not exceeding $38 \mu \mathrm{m}$, were injected intraperitoneally in mice. P-PLLA particles were obtained by $25 \mathrm{kGy} \gamma$-irradiation of N-PLLA particles. N-PLLA and P-PLLA particles were injected using an $0.3 \%$ ethanol $/ 0.9 \%$ saline solution intraperitoneally to the mice. We also studied the release of the absorbed ethanol as a possible model for the release of low molecular weight, potentially toxic products. As control, nondegradable polytetrafluoroethylene (PTFE) particles and the carrier solution were used. After 1, 2, 3, 4, 5 , and 7 days, the cells of the abdominal cavity were harvested to study the effect of phagocytosis of polymer particles on phagocytic cell morphology and viability Studies with transmission electron microscopy indicated that, upon injection of particles in the peritoneal cavity, macrophages demonstrated signs of cell damage, cell death, and cell lysis due to phagocytosis of a large amount of P-PLLA particles. The morphology of the cells that had phagocytosed the N-PLLA and PTFE particles did not differ substantially from those of control animals in which only the solution was injected. Also, in the controls, hardly any cell death and no debris was observed. When the PLLA particles were injected as a suspension in a $0.3 \%$ ethanol/0.9\% saline solution, no difference was observed between N-PLLA and P-PLLA. After phagocytosis, both cause cell damage, sometimes leading to cell death. The highest numbers of necrotic cells were observed on day 2 . The effects could be caused by the (peak) release of degradation products from P-PLLA fragments or by the release of the absorbed ethanol when the 0.3 ethanol/0.9 saline solution was used to administer the particles. In conclusion, it can be stated that cell damage, sometimes leading to cell death, may be caused by phagocytosed poly(L-lactic acid) particles. (c) 1993 John Wiley \& Sons, Inc.

\section{INTRODUCTION}

The inflammatory response against an implanted biomaterial polymeric is determined by many factors, such as the implantation site, ${ }^{1}$ shape $_{,}{ }^{2}$ wettability, ${ }^{3}$ and toxicity. 4,5

The degradability of the polymer is also an important factor, determining the type and intensity of the inflammatory response. The appearance of particles, poly-, oligo-, and monomers released during degradation of a polymer in vivo correlates with an observed change of the type and / or intensity of a preexisting inflammatory response. ${ }^{6}$ This may be caused by degradation products, toxic to cells ${ }^{5}$ or a change in roughness and shape during the release of fragments. ${ }^{2}$ Moreover, the phagocytosis of the fragments them-

*To whom correspondence should be addressed. selves may play an important role in the modification of the inflammatory response.

It has been demonstrated that the macrophage plays a prominent role in the resorption process by phagocytosing fragments of polymeric materials. ${ }^{7,8}$ Phagocytosis modifies the functional status of the macrophage, which is known to play a pivotal role in both the inflammatory response at tissue level ${ }^{10}$ and in the foreign body reaction. The giant cells observed in this foreign body reaction are formed by fusion of macrophages, ${ }^{11}$ a process mediated by several cytokines (IL-4 and IFN- $\gamma$ ), ${ }^{12-14}$ but not yet fully understood. Phagocytosis of polymer fragments may also cause cell death. The release of the contents of dead cells may cause a renewed acute inflammatory response.

The effects of phagocytosis can be studied in vitro and in vivo. A major disadvantage of in vitro studies is 
the absence of interaction with relevant physiological systems of the host, e.g., the immune system. Subcutaneous implants provoke a complex tissue reaction, making it difficult to isolate and study the resorption process on a cellular level.

In this study, an in vivo model, modified from a model originally described by Pizzoferrato et al., ${ }^{15}$ was used to investigate the effect of phagocytosis of P-PLLA and N-PLLA particles on intraperitoneal cells upon injection in the peritoneal cavity. This model combines the advantages of in vivo and in vitro studies. However, it may be difficult to distinguish macrophages from neutrophils and atypical B-lymphocytes. To facilitate the distinction, an immunoelectron microscopy double staining procedure was employed, using an anti-Mac-1 monoclonal antibody $(\mathrm{mAb}),{ }^{16-18}$ which is specific for macrophages, and an anti-mouse-IgM $\mathrm{mAb}$ to detect B-lymphocytes.

PLLA has a relatively slow degradation rate. Therefore, PLLA was predegraded in an attempt to obtain a higher amount of low molecular weight polymer degradation products. Also, PLLA particles were injected using an ethanol/saline solution in order to obtain a standard amount of particles injected and to investigate the effect of the release of the absorbed ethanol as a possible model for the release of low molecular weight potentially toxic products. Polytetrafluoroethylene (PTFE) particles in the same size range were used as control, as PTFE is considered to be nondegradable.

In this study, PLLA and PTFE particles were injected intraperitoneally in mice and the effect of phagocytosis on the morphology of the cells, as an indication of the viability of the cells was studied over a 7 day period.

\section{MATERIALS AND METHODS}

\section{PLLA and PTFE}

PLLA with an $\mathrm{M}_{v}$ of $50,000^{19}$ was obtained commercially (Purac Biochem B.V., Gorinchem, The Netherlands). Particles were made by grinding bulk PLLA and their size was limited using a sieve (Endecotts, USA) with an aperture size of $38 \mu \mathrm{m}$ (A.S.T.M. E.11).

Predegraded PLLA (P-PLLA) particles were obtained by $y$-irradiation of the PLLA particles to a total dose of $25 \mathrm{kGy}$ (Gammaster, The Netherlands). The parameters of (the initial) N-PLLA and predegraded P-PLLA, determined using gel permeation chromatography ${ }^{20}$ and differential scanning calorimetry were as shown in Table I.

PTFE particles (size range 4-9 $\mu \mathrm{m}$ ) were obtained commercially (Goodfellow Ltd., Cambridge, England) and were used as control.
TABLE I

Base Parameters of N-PLLA and P-PLLA

\begin{tabular}{lcc}
\hline Parameter & N-PLLA & P-PLLA \\
\hline $\mathrm{M}_{\mathrm{w}}$ & 99,000 & 53,100 \\
$\mathrm{M}_{\mathrm{n}}$ & 44.590 & 27,400 \\
$\mathrm{M}_{\mathrm{w}} / \mathrm{M}_{\mathrm{n}}$ & 2.2 & 2.0 \\
$\mathrm{~T}_{\mathrm{m}}$ & $183^{\circ} \mathrm{C}$ & $172^{\circ} \mathrm{C}$ \\
Heat of fusion & $64.0 \mathrm{~J} / \mathrm{g}$ & $66.8 \mathrm{~J} / \mathrm{g}$ \\
\hline
\end{tabular}

\section{Surface morphology of PLLA and PTFE}

The morphology of the particles was examined using a scanning electron microscope (SEM). N-PLLA, P-PLLA, and PTFE powder were therefore mounted on specimen holders using double adhesive tape, sputter-coater with gold (Balzers 07 120B) and subsequently examined in a DS 130 (ISI) SEM operated at $10 \mathrm{kV}$.

\section{Experimental procedure}

Male Balb/c mice, obtained from the Central Animal Laboratory, University of Groningen, The Netherlands, and weighing approximately $40 \mathrm{~g}$, were injected intraperitoneally with one of the following samples: A. nontreated PLLA (N-PLLA) particles not suspended in solution. Approximately $5 \mathrm{mg}$ of N-PLLA particles were injected in the intraperitoneal cavity of each mouse using the air in the syringe; B. predegraded PLLA (P-PLLA) particles not suspended in solution and injected as described above. Approximately $5 \mathrm{mg}$ of P-PLLA particles were injected in each mouse; C. $5 \mathrm{mg}$ of N-PLLA particles suspended in solution prepared by suspending N-PLLA in $100 \%$ ethanol (distilled using $\mathrm{Na}$ to adsorb $\mathrm{H}_{2} \mathrm{O}$ ) and subsequently adding a sterile and pyrogen free $0.9 \%$ saline solution, resulting in a $10 \mathrm{mg}$ PLLA per $\mathrm{ml} 0.3 \%$ ethanol/0.9\% saline solution; D. $5 \mathrm{mg}$ of P-PLLA particles suspended in solution prepared as described above; E. PTFE particles not suspended in solution and injected as described under A. Approximately $5 \mathrm{mg}$ was injected in each mouse; F. the $0.3 \%$ ethanol $/ 0.9 \%$ saline solution as control.

For each time interval and parameter in each group, three mice were used. The mice had free access to standard mouse food and water. All national rules concerning the use and care of laboratory animals have been observed.

The mice were sacrificed and the peritoneal cells were harvested with a peritoneal lavage after $1,2,3$, 4,5 , or 7 days, using $5 \mathrm{~mL}$ phosphate buffered saline (PBS) for each mouse. Cells of three mice for each time interval and parameter were pooled. 

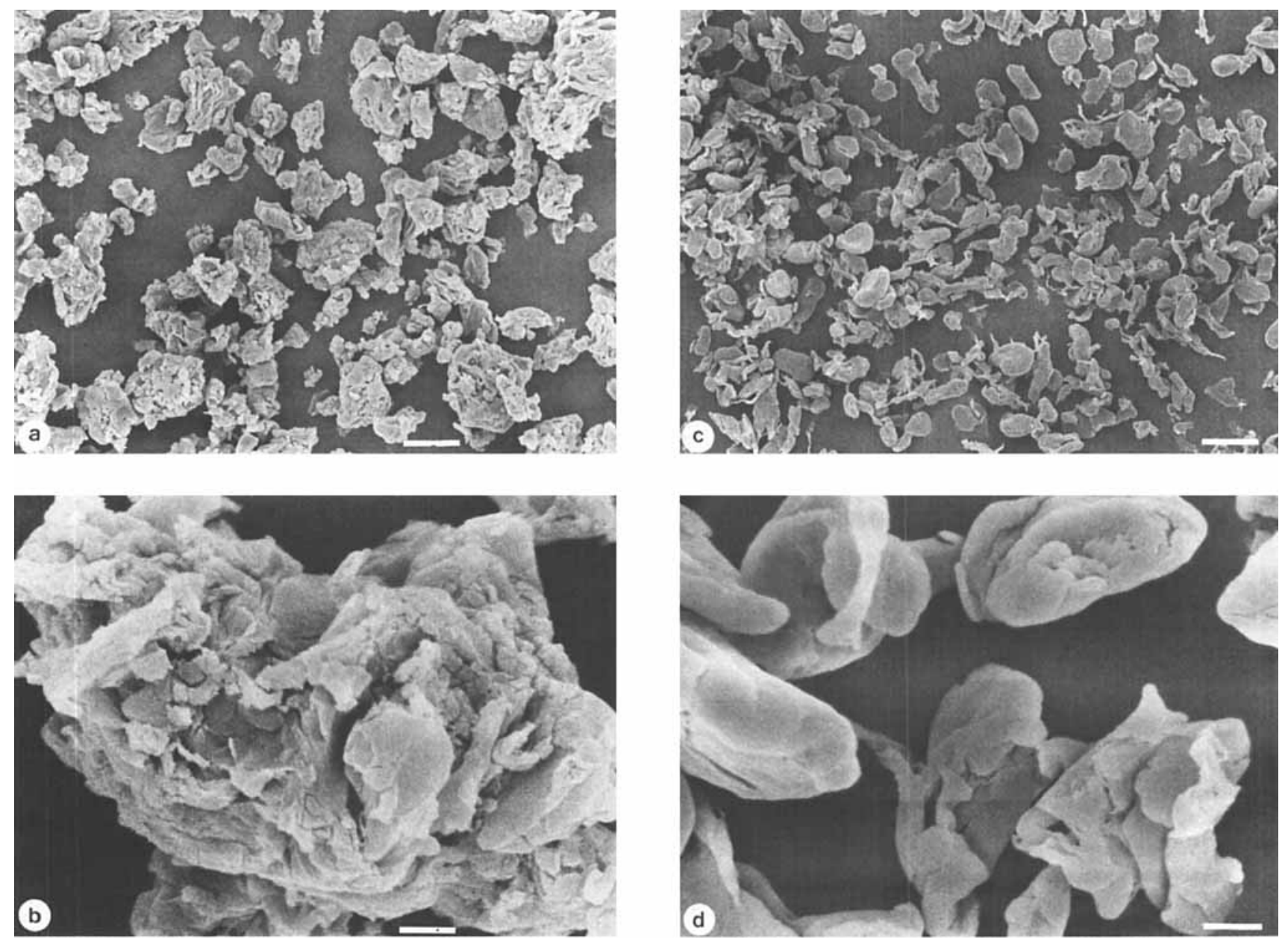

Figure 1. Scanning electron micrograph of: a. Nontreated PLLA particles (N-PLLA). The size of the largest particles is approximately $40 \mu \mathrm{m}$. Bar indicates $20 \mu \mathrm{m}$. b. Nontreated PLLA particle at high magnification. Note the roughness of the surface. Bar indicates $2 \mu \mathrm{m}$. c. PTFE particles. The size of the largest particles are approximately $10 \mu \mathrm{m}$. Bar indicates $20 \mu \mathrm{m}$. d. PTFE particles at high magnification. Note the difference in surface roughness with the PLLA particle (Fig. 1[b]). Bar indicates $2 \mu \mathrm{m}$.

\section{Cell characterization}

Cells were characterized using a preembedding immunogold labelling technique, except for the samples from mice in which not-suspended N-PLLA and not-suspended P-PLLA particles were injected (groups A and B). These cells were fixed immediately after harvesting with $2 \%$ glutaraldehyde in a $0.1 \mathrm{M}$ Na-cacodylate, $0.1 \mathrm{M}$ sucrose, $\mathrm{pH} 7.4$, buffer and processed for transmission electron microscopy (TEM).

Cells from the other mice (group C, D, E, and F) were fixed in a $1 \%$ paraformaldehyde phosphate buffered saline (PBS) and rinsed three times with a $1 \%$ bovine serum albumin (BSA) (Cooper Biomedical, U.S.A.) and PBS (1\% BSA/PBS) solution. After centrifugation and removal of the supernatant, the cells were resuspended in $70 \mu \mathrm{L}$ rat anti-Mac-1 mAb $\left(\operatorname{IgG}_{2 \mathrm{a}}\right)$ (Seralab, England). Subsequently, $70 \mu \mathrm{L}$ goatanti-mouse IgM coupled to $10 \mathrm{~nm}$ gold (GAM IgM 10) (Aurion, The Netherlands) and diluted with $1 \%$ BSA/PBS to 1:5, was added. After incubation for $1 \mathrm{~h}$ at room temperature, the antibody solutions were removed and the cells were subsequently washed three times with $1 \%$ BSA/PBS. The cells were then incubated for $1 \mathrm{~h}$ at room temperature, with goat-antirat IgG coupled to $20 \mathrm{~nm}$ gold (GAR IgG 20) (Biorad Microscience Division, England) and diluted with 1\% BSA/PBS to 1:10, in order to visualize the labelling with anti-Mac-1. After rinsing, the cells were fixed in $2 \%$ glutaraldehyde in a $0.1 \mathrm{M}$ Na-cacodylate, $0.1 \mathrm{M}$ sucrose, $\mathrm{pH} 7.4$, buffer.

Stable cell pellets of all samples were obtained upon solidification in a $2 \%$ agar (Difco, USA) solution in which the cells were centrifuged.

Cell pellets in agar from all mice (group $A$ to $F$ ) were postfixed in a $1: 1 \mathrm{v} / \mathrm{v}$ mixture of $1 \% \mathrm{OsO}_{4}$ and $1 \% \mathrm{~K}_{4} \mathrm{Fe}(\mathrm{CN})_{6}$ in $0.1 \mathrm{M} \mathrm{Na}$-cacodylate buffer. ${ }^{21,22}$ The cells were then dehydrated in a graded ethanol series followed by butyl-2,3-epoxypropylether ${ }^{23}$ and subsequently embedded in Epon. Sections of $50-100 \mathrm{~nm}$, obtained on a LKB ultramicrotome equipped with a diamond knife (Diatome) were examined in a trans- 

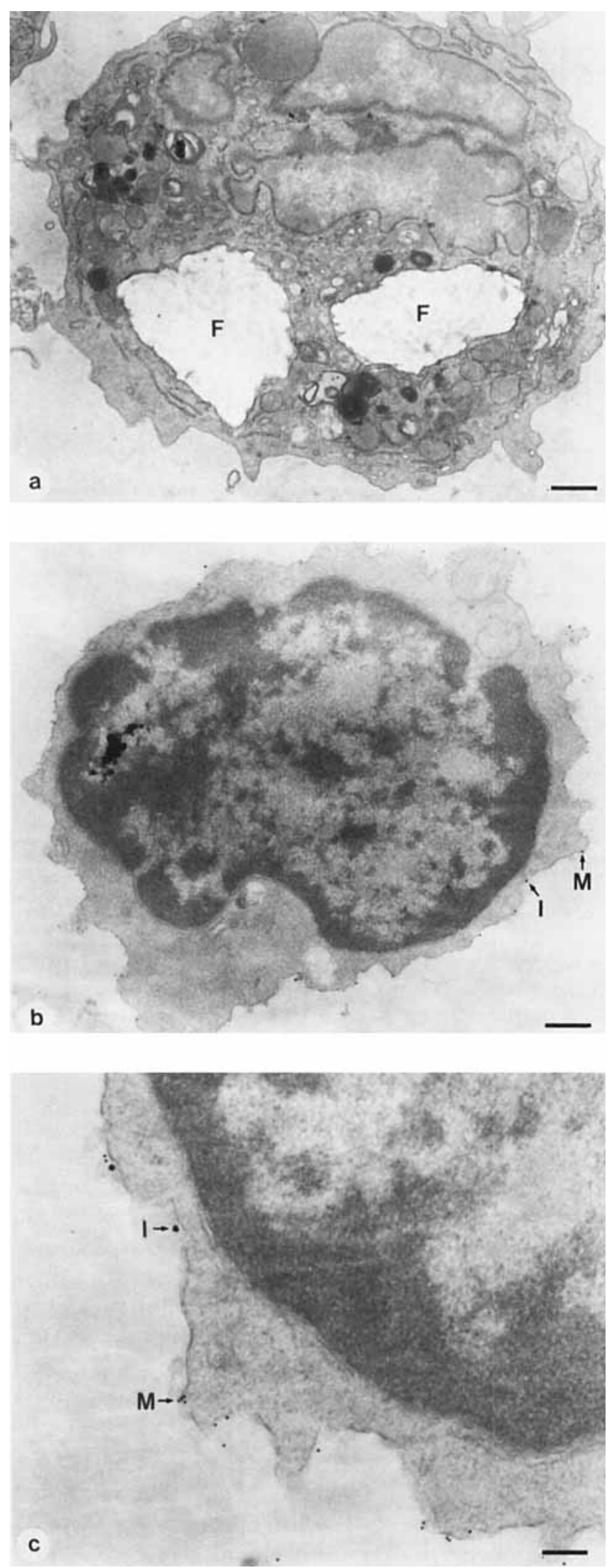

Figure 2. Transmission electron micrograph of: a. Neutrophilic granulocyte. Note the phagocytosed N-PLLA fragments (F). Bar indicates $0.6 \mu \mathrm{m}$. b. An atypical B-lymphocyte stained for IgM $(10 \mathrm{~nm}$ gold particles, I) and Mac-1 (20 nm gold particles, M). Bar indicates $0.6 \mu \mathrm{m}$. c. The atypical lymphocyte at higher magnification. Bar indicates $0.15 \mu \mathrm{m}$.
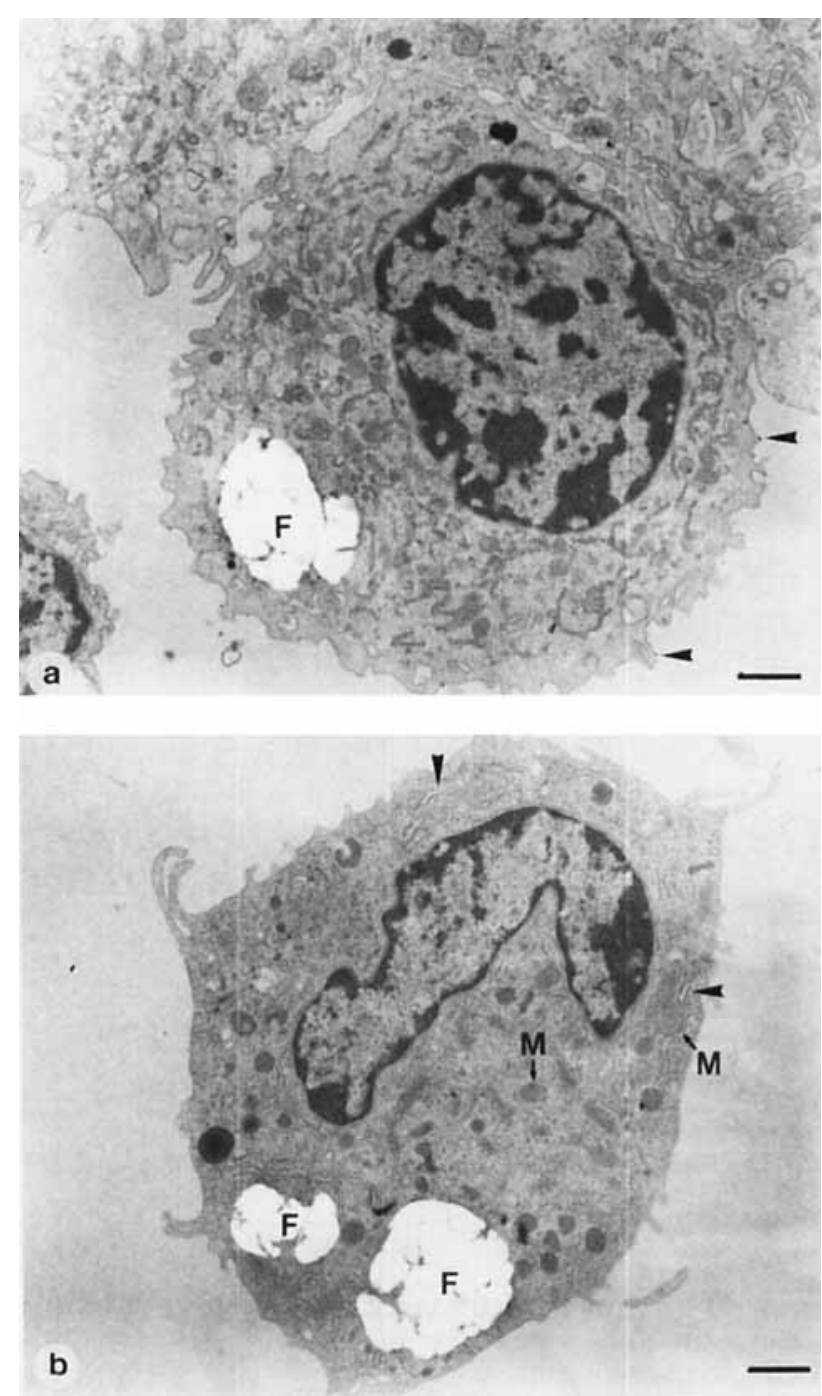

Figure 3. Predegraded PLLA particles (F) at day 5: a. Injected as a suspension in a $0.3 \%$ ethanol $/ 0.9 \%$ saline solution (group D). The cell shows no signs of damage. Note the staining for Mac-1 (arrow heads). F = P-PLLA fragment. Bar indicates $1 \mu \mathrm{m}$. b. Injected directly (group B). Note the necrotic state of the cells as indicated by the swollen mitochondria (M) and widened rough endoplasmatic reticulum (arrow heads). $\mathrm{F}=$ P-PLLA fragment. Bar indicates $1 \mu \mathrm{m}$.

mission electron microscope (Akashi 002A) operated at $60 \mathrm{kV}$. The morphology of macrophages and neutrophilic granulocytes after phagocytosis of PLLA or PTFE particles was examined as an indication of their functional state. A number of 500 cells were examined for each group and time interval.

\section{RESULTS}

\section{Surface morphology of PLLA and PTFE}

There was no difference in surface morphology between the N-PLLA and P-PLLA particles. PLLA 
particles (Fig. 1[a,b]) appear to have a rougher surface than PTFE particles (Fig. 1[c, d]), with more clefts and sharp edges. The size of the largest PLLA fragment is approximately $40 \mu \mathrm{m}$ and of the largest PTFE fragment approximately $10 \mu \mathrm{m}$.

\section{Cell characterization}

Using anti-Mac- $1 \mathrm{mAb}$ and anti-mouse-IgM the distinction between neutrophils (Fig. 2[a]), macrophages, and atypical B-lymphocytes (Fig. $2[\mathrm{~b}, \mathrm{c}]$ ) as made on morphological criteria, could be verified, because neutrophils usually stain weakly positive for Mac-1 and not for IgM, atypical B-lymphocyes stain weakly positive for Mac-1 and strongly positive for IgM (Fig. 2b), and macrophages only stain strongly positive for Mac1 (Fig. 3[a]).

\section{Morphology of the cells}

The percentage of the number of cells observed containing a particle varied from $5 \%$ at day 1 to less than $1 \%$ at day 7 for all groups, except in group $F$. The results are summarized in Table II.

After phagocytosis, more cell death and more cell debris were observed when P-PLLA (group B) was compared to N-PLLA) (group A) or PTFE (group E), especially on day 3 and day 4 . However, in most cells observed, the signs of cell damage were limited to changes in cell organelles, such as swollen mitochondria, widened rough endoplasmatic reticulum, and the disappearance of membrane ruffling, in some cases even still visible on day 5 (Fig. 3[b]). A high extent of the cell damage, eventually leading to cell death appears to be related with a high amount of phagocytosed P-PLLA fragments.

The highest number of necrotic cells, showing lytic changes and the highest amount of cell debris was observed for the cells from the test animals using N-PLLA or P-PLLA particles suspended in the $0.3 \%$ ethanol/0.9\% saline solution (group $\mathrm{C}$ and $\mathrm{D}$ ), on day 2 and 3 . There was no difference between $\mathrm{N}$ PLLA (group C) (Fig. 4[a]) and P-PLLA (group D) (Fig. $4[\mathrm{~b}]$ ). Again, a high extent of the cell damage, eventually leading to cell death, appears to be related with a high amount of phagocytosed N-PLLA or PPLLA fragments.

Using PTFE particles (group E) (Fig. 5[a, b]) or controls not containing any particles (group F), only small numbers of cells showing lytic changes were observed and almost no cell debris. The morphology of the cells having phagocytosed N-PLLA (group A) only showed minimal increase in signs of cell damage compared to the control (group F).

At day 7, no more cells showing lytic changes or cell debris were observed, both in the test animals and in the controls. Even the small amounts of macrophages carrying a phagocytosed PLLA fragment previously suspended in $0.3 \%$ ethanol $/ 0.9 \%$ saline solution have a normal morphology, sometimes already observed on day 5 (Fig. 3[a]).

In all cases, it was observed that both granulocytes and macrophages phagocytosed PLLA and PTFE particles. Cell death of the macrophages appears to be related to the type and amount of material phagocytosed. This amount can consist of one single large fragment or many smaller ones. In all test animals, a small amount of phagocytosed PLLA seems to be well tolerated by macrophages (Fig. 6), when N-PLLA or P-PLLA is used and whether or not the particles are suspended in a $0.3 \%$ ethanol $/ 0.9 \%$ saline solution.

Clusters of cells attempting to process large PLLA particles were also observed (Fig. 7[a]). The membranes sometimes interacts very closely, strongly suggesting fusion of the cells (Fig. $7[b]$ ), which can be the beginning of giant cell formation.

\section{DISCUSSION}

Using not-suspended PLLA particles, the difference in cell morphology after phagocytosis between P-PLLA (group B) and N-PLLA (group A) or PTFE (group E) was obvious. The cells which had phago-

TABLE II

Classification of the Number of Cells Containing Particles (Except for Group F) Demonstrating Cumulative Changes in Cell Morphology after Intra-Peritoneal Injection of the Particles or Control Solution

\begin{tabular}{ccccc}
\hline Group & Particle and/or Solution & Changes in Cell Organelles & $\begin{array}{c}\text { Cell Content } \\
\text { Barely Distinguishable }\end{array}$ & $\begin{array}{c}\text { Cell Disintegrated, } \\
\text { Forming Debris }\end{array}$ \\
\hline A & N-PLLA & 1 & 0 & 0 \\
B & P-PLLA & 2 & 1 & 1 \\
C & N-PLLA in solution & 3 & 2 & 1 \\
D & P-PLLA in solution & 3 & 2 & 1 \\
E & e-PTFE & 0 & 0 & 0 \\
F & solution & 0 & 0 & 0 \\
\hline
\end{tabular}

$0=0-1 \%, 1=1-25 \%, 2=25-50 \%, 3=50-75 \%, 4=75-100 \%$. Per group and time interval a number of 500 cells were observed. Up till $5 \%$ of the peritoneal cells observed contained a particle. Therefore, the results are based on a number of 25 cells which contain a polymer particle per group and per time interval. 

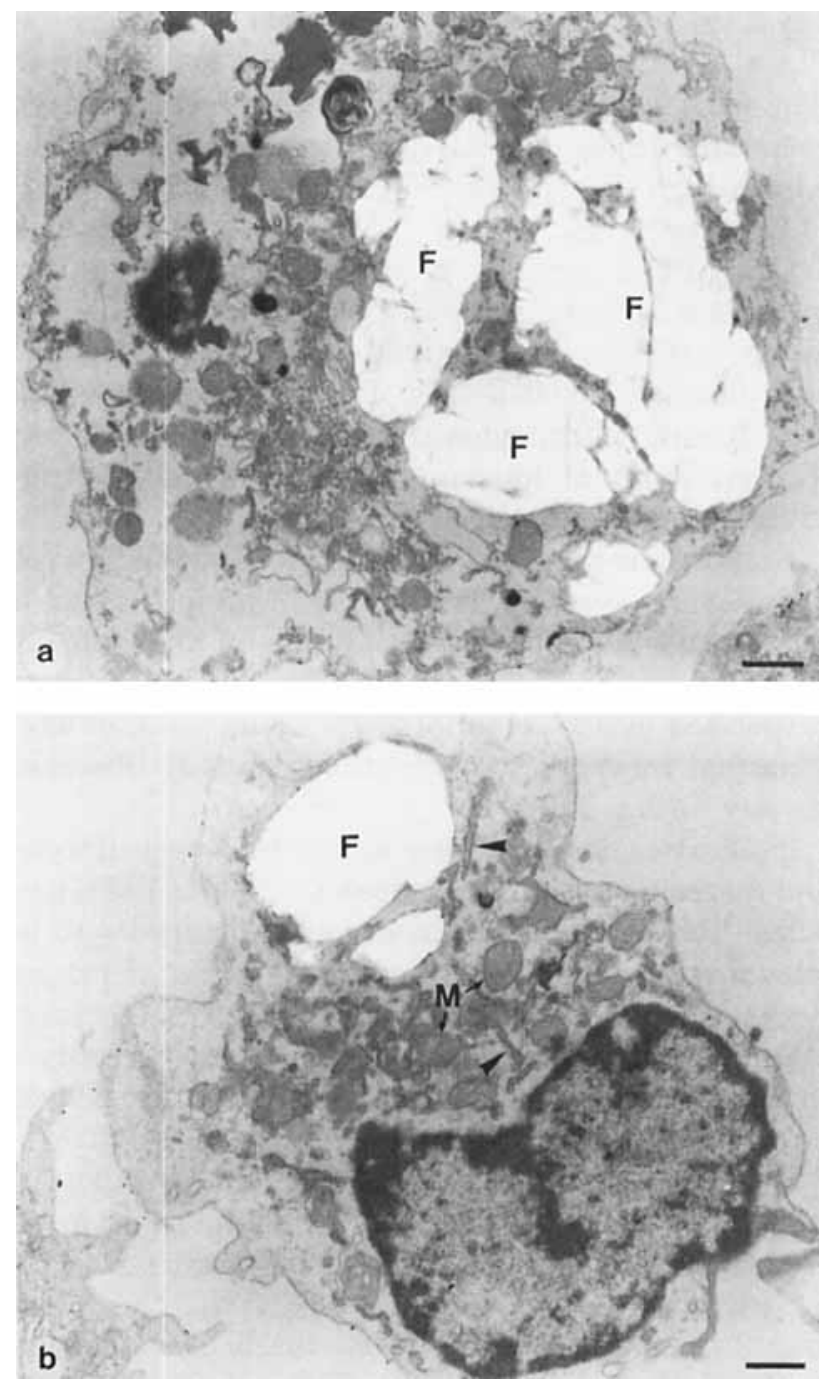

Figure 4. Transmission electron micrograph of phagocytosed PLLA particles (F), injected as a suspension in a $0.3 \%$ ethanol $/ 0.9 \%$ saline solution, at day 3 : a. Nontreated (N-PLLA, group C). Note the disintegration of the cell. Bar indicates $0.7 \mu \mathrm{m}$. b. Predegraded (P-PLLA, group D). Bar indicates $0.6 \mu \mathrm{m}$. Note the necrotic state of the cells, indicated by swollen cell organelles, especially mitochondriae $(M)$ and widened rough endoplasmatic reticulum (arrow heads).

cytosed P-PLLA showed more morphological signs of cell damage. It is remarkable that most necrotic cells and cell debris were observed on days 3 and 4. However, signs of cell damage, such as swollen mitochondria, widened rough endoplasmatic reticulum, and disappearance of membrane ruffling, were present from day 2 . This difference in morphology is probably caused by degradation products from P-PLLA, as suggested by the difference in the parameters $\left(M_{w}\right.$ and $\left.M_{n}\right)$ before and after $\gamma$-irradiation. The lag-time between phagocytosis and the effects of this process indicates that a minimal amount of time is needed for the infiltration of the predegraded PLLA particles with enough cellular fluid, in which degradation products can be released. This is consis-
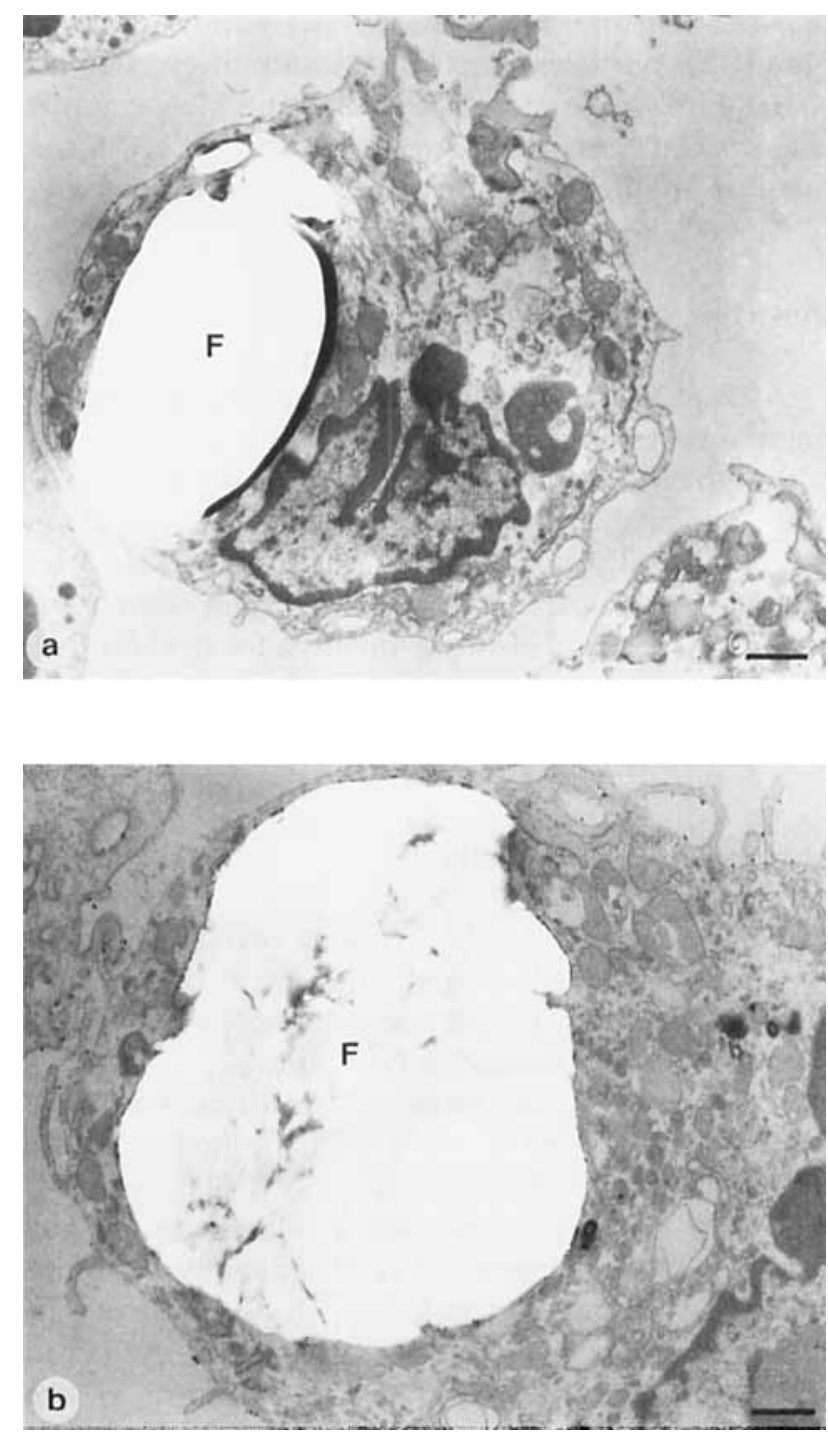

Figure 5. Transmission electron micrograph of phagocytosed PTFE particles (F) (group E): a. At day 3. The PTFE fragment is lost due to heating in the beam of the electron microscope. The cell, although showing signs of damage, is still in better shape than those shown in Fig. 4. Bar indicates $0.7 \mu \mathrm{m}$. b. At day 4. Although a large PTFE fragment is phagocytosed, the cell shows no signs of damage. Bar indicates $0.6 \mu \mathrm{m}$.

tent with our findings in previous experiments using PLLA. ${ }^{24}$ The favorable results with N-PLLA particles (group A) indicated that under normal physiological conditions probably the concentration of degradation products released from phagocytosed PLLA particles did not reach toxic concentrations in the cell.

The difference in the morphology of the macrophages after phagocytosis between P-PLLA (group C) or N-PLLA particles (group D) and N-PLLA (group A) or PTFE (group E) is also clear. The cells which had phagocytosed P-PLLA or N-PLLA particles previously suspended in the ethanol/saline solution showed more morphological signs of cell damage. This is probably caused by the release of ethanol from the phagocytosed particles. 

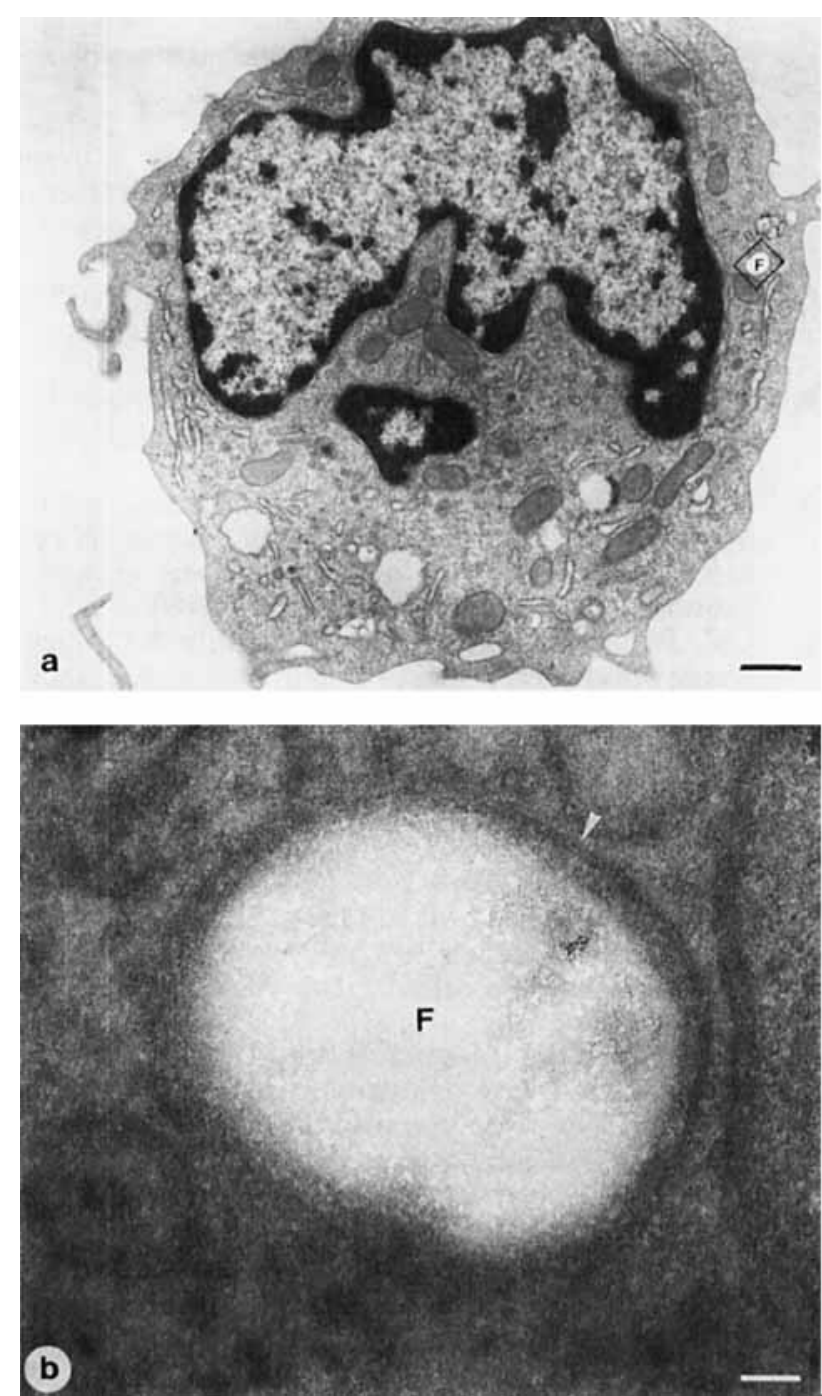

Figure 6. a. Macrophage with a small N-PLLA fragment $(\mathrm{F})$ which was injected as a suspension in a $0.3 \%$ ethanol/0.9\% saline solution (group C). Bar indicates $0.6 \mu \mathrm{m}$. b. Phagosome containing the PLLA fragment (F). Note the bilayer of the lipid membrane (arrow heads). Bar denotes $30 \mathrm{~nm}$.

For all the test animals (group A to E), injected particles were apparently cleared from the abdominal cavity at day 7 . Only an occasional macrophage with a phagocytosed polymer fragment was observed. The polymer particles, whether phagocytosed or not, had probably entered the lymphatic system ${ }^{25,26}$ of the $a b-$ domen. Larger particles may have been deposited on the walls of the peritoneal cavity. Cell morphology of the macrophages having phagocytosed a fragment, or possibly having rephagocytosed a polymer fragment upon release from a dead cell, appeared normal. Apparently, the rate of degradation products or ethanol release is within the handling capacity of the cell.

The results demonstrate that phagocytosed PLLA particles can cause cell death. Granulocytes are shortliving cells and their cell death observed may not be the consequence of phagocytosis of PLLA particles.
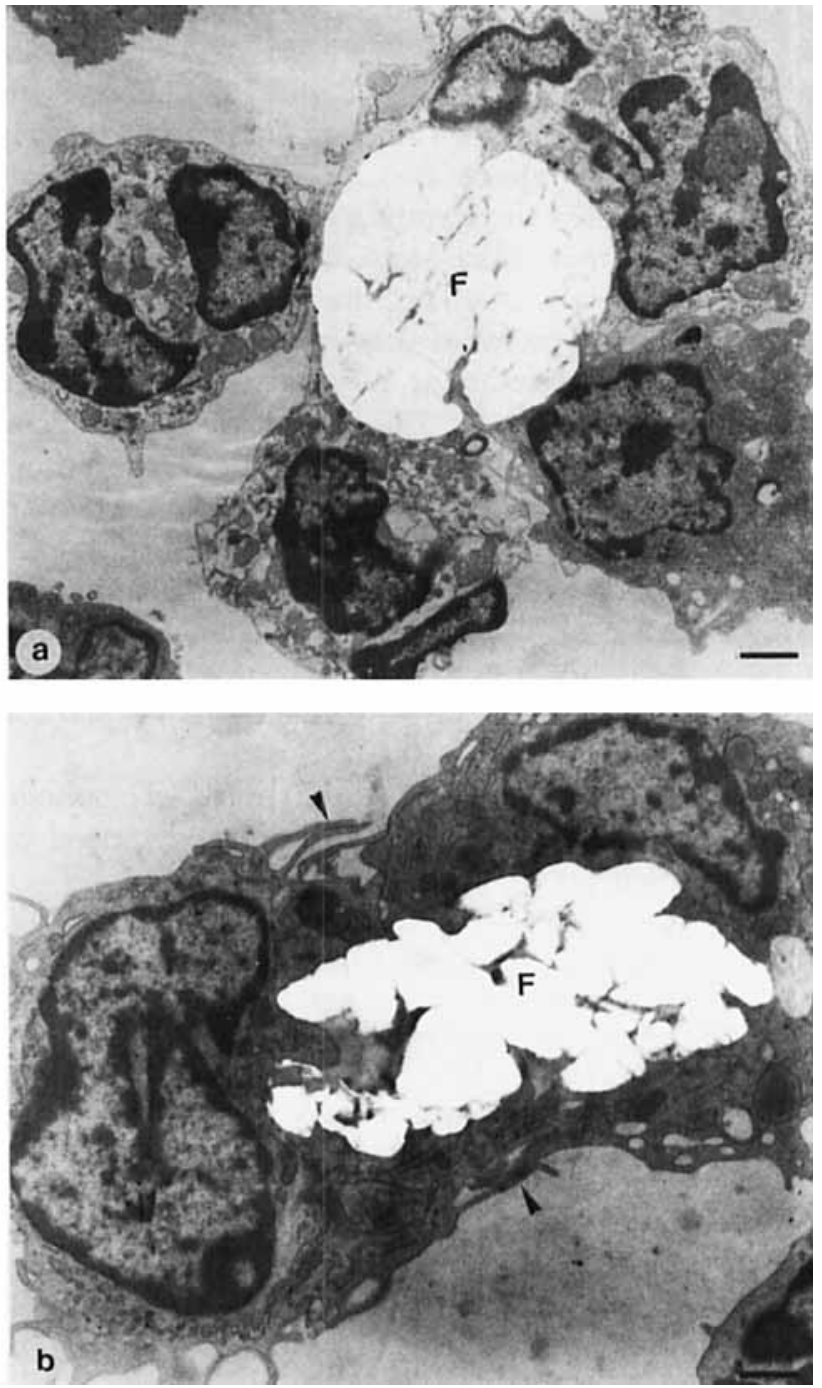

Figure 7. Multiple macrophages surrounding a P-PLLA fragment (F) injected as a suspension in a $0.3 \%$ ethanol/0.9\% saline solution (group D) at day 1. Bar indicates $1.2 \mu \mathrm{m}$. b. Two macrophages in a joint effort to phagocytose a N-PLLA fragment (F) injected as a suspension in a $0.3 \%$ ethanol $/ 0.9 \%$ saline solution (group C). Note the intertwining of the cell membranes (arrowhead). This may be the beginning of giant cell formation. Bar indicates $0.7 \mu \mathrm{m}$.

However, macrophages are long-lived phagocytes ${ }^{9,10}$ and they also showed lytic changes.

The damage to cells caused by PLLA particles may be caused also by mechanical stress. However, the mechanical component appears to be of less importance in explaining the phenomena observed. The phagocytosed N-PLLA particles (group A), which have a rougher surface, almost cause the same cellular response as phagocytosed PTFE particles (group E). Perhaps roughness at the submicron level is more important in exerting mechanical damage to the cell membrane.

In this study, the effects of the degradation products of PLLA were studied at the level of the individ- 
ual cell. However, there are many more factors to be considered when the effects of degradation are studied in tissues or organs. Parameters such as the dilution or concentration of degradation products in the extracellular space also determine the ultimate effect on the cells surrounding the implant. Phagocytosis of fragments also occur in tissues and organs. This leads to a change in the functional status of the macrophage or cell death. In their turn, both can trigger an aggravation or renewal of the acute inflammatory response. ${ }^{9,10}$ This effect may contribute to the varying intensity and nature of the inflammatory response upon the degradation of PLLA in particular ${ }^{6}$ and perhaps other polymers in general. The rate of degradation of an implanted polymer determines the rate of release of degradation products such as fragments. Therefore, controlling the degradation rate is important for controlling the inflammatory reaction and biocompatibility.

In conclusion it can be stated that cell damage, sometimes leading to cell death, may be caused by phagocytosed poly(L-lactic acid) particles.

The authors acknowledge J. A. Oosterbaan for his assistance with the transmission electron microscopical procedures, F. Dijk for his assistance with the scanning electron microscopical procedures, D. Huizinga, H. Meiborg, and P. van der Sijde for their expert assistance with the preparation of the photographs, Dr. F.G.M. Kroese for his advise on the use of and interpretation of the results of the antiMac-1 mAb, Prof. P. Christel and Prof. J. M. Anderson for their valuable critical comments on the experimental design, and Prof. I. Molenaar for his valuable comments on the manuscript.

\section{References}

1. D. Bakker, C. A. van Blitterswijk, S. C. Hesseling, J. J. Grote, and W.T. Daems, "Effect of implantation site on phagocyte/polymer interaction and fibrous capsule formation," Biomaterials, 9, 14-23 (1988).

2. B. F. Matlaga, L.P. Yasenchak, T.N. Salhouse, "Tissue response to implanted polymers: the significance of shape," J. Biomed. Mat. Res., 10, 391-397 (1976).

3. J.M. Schakenraad, H. J. Busscher, C.R.H. Wildevuur, and J. Arends, "The influence of substratum free energy on growth and spreading of human fibroblast in the presence and absence of serum proteins," J. Biomed. Mat. Res., 20, 773-784 (1986).

4. R.E. Marchant, J.M. Anderson, and E. O. Dillingham, "In vivo biocompatibility studies. VII. Inflammatory response to polyethylene and to cytotoxic polyvinylchloride," I. Biomed. Mat. Res., 20, 37-50 (1986).

5. P.B. van Wachem, M. J. A. v. Luyn, P. Nieuwenhuis, H. K. Koerten, L. Olde Damink, H. Ten Hoopen, and J. Feijen, "In vivo degradation of processed dermal sheep collagen evaluated with transmission electron microscopy," Biomaterials, 12, 215-223 (1991).

6. J.M. Schakenraad, J. A. Oosterbaan, P. Nieuwenhuis, I. Molenaar, J. Olijslager, W. Potman, M. J.D.
Eenink, and J. Feijen, "Biodegradable hollow fibres for the controlled release of drugs," Biomaterials, 9, 116-120 (1988).

7. F. R. Rozema, W. C. de Bruijn, R. R. M. Bos, G. Boering, A.J. Pennings, "Late tissue response to boneplates and screws of poly(L-lactide) used for fracture fixation of the zygomatic bone plate," Advances in Biomaterials, 10, 349-355.

8. J.M. Anderson and K. M. Miller, "Biomaterial biocompatibility and the macrophage," Biomaterials, 5, 5-10 (1984).

9. J. Schnyder and M. Baggiolini, "Role of phagocytosis in the activation of macrophages," J. Exp. Med., 148, 1449-1457 (1978).

10. R. S. Cotran, V. Kumar, and S. L. Robbins, "Inflammation and repair," in Pathological Basis of Disease, R.S. Cotran, V. Kumar, and S. L. Robbins (ed.), V. B. Saunders, Philadelphia, pp. 39-86 (1989).

11. J.M. Papadimitriou and M.N.-I. Walters, "Macrophage polykarya," CRC Crit. Rev. Toxicol., 9, 211-255 (1979).

12. N.F. Hassan, N. Kamani, M. M. Meszaros, and S.D. Douglas, "Induction of multinucleated giant cell formation from human blood-derived monocytes by phorbol myristate acetate in in vitro culture," J. Immunol., 143, 2179-2184 (1989).

13. A. McInnes and D.M. Rennick, "Interleukin 4 induces cultured monocytes/macrophages to form giant multinucleated cells," J. Exp. Med., 167, 598-611 (1988).

14. J. Most, H.P. Neumayer, and M.P. Dierich, "Cytokine-induced generation of multinucleated giant cells in vitro requires interferon- $\gamma$ and expression of LFA-1," Eur. J. Immunol., 20, 1661-1667 (1990).

15. A. Pizzoferrato, A. Vespucci, G. Ciapetti, S. Stea, C. Tarabusi, "The effect of injection of powdered biomaterials on mouse peritoneal cell populations," J. Biomed. Mat. Res., 21, 419-428 (1987).

16. K. L. Holmes and H.C. Morse III, "Murine hematopoietic cell surface antigen expression," Immunology Today, 9, 344-350 (1988).

17. T. Springer, G. Galfre, D.S. Secher, and C. Milstein, "Monoclonal xenogeneic antibodies to murine cell surface anigens: identification of novel leukocyte differentiation antigens," Eur. J. Immunol., 8, 539-551 (1978).

18. D.I. Beller, T.A. Springer, and R.D. Schreiber, "Anti-Mac-1 selectively inhibit the mouse and human type three complement receptor," J. Exp. Med., 156, 1000-1009 (1982).

19. A. Schindler and D. Harper, "Polylactide. 2. Visocosity-molecular weight relationships and unperturbed chain dimensions," J. Polym. Sci., 17, 2593-2599 (1979).

20. J.M. Schakenraad, P. Nieuwenhuis, I. Molenaar, J. Helder, P. J. Dijkstra, and J. Feijen, "In vivo and in vitro degradation of glycine/DL-lactic acid copolymers," J. Biomed. Mat. Res., 23, 1271-1288 (1989).

21. C. E. Hulsteart, D. Kalicharan, and M. J. Hardonk, "Cytochemical demonstration of phorphatases in the rat liver by a cerium-based method in combination with osmium tetroxide and potassium ferrocyanide postfixation," Histochemistry, 78, 71-79 (1983).

22. M. J. Karnovsky, "Use of ferrocyanide-reduced $\mathrm{OsO}_{4}$ in electron microscopy, Abstracts of the 11th annual meeting," Am. Soc. Cell. Biol., New Orleans, 146 (1971). 
23. E.H. Blaauw, J. A. Oosterbaan, and J.M. Schakenraad, "Improved epon embedding for biomaterials," Biomaterials, 10, 356-358 (1989).

24. K. H. Lam, H. Esselbrugge, J. Feijen, P. J. Dijkstra, P. Nieuwenhuis, I. Molenaar, and J.M. Schakenraad, "Biodegration of porous versus non-porous poly (Llactic acid) films," J. Mat. Sci.: Mat. Med. 1993 (in press).

25. M. Kotani, M. Rai, and S. Nakao, "Observations with the electron microscope on the absorption of
Indian ink from the peritoneal cavity of the rabbit," Okajimas Folia Anatomica Japonica, 38, 149-173 (1962).

26. M. Kotani, K. Okada, H. Fujii, H. Tsuchiya, K. Matsuno, S. Ekino, and S. Fukada, "Lymph macrophages enter the germinal center of lymph nodes of guinea pigs," Acta Anat., 99, 391-402 (1977).

Received February 8, 1993

Accepted July 23, 1993 